\title{
Comparison of Short-term Outcomes of Percutaneous Coronary Intervention between Young Male and Female Patients with Acute Coronary Syndrome
}

\author{
Fathima Aaysha Cader ${ }^{1}$, Afzalur Rahman², Mohammad Arifur Rahman ${ }^{3}$, Shahana Zaman ${ }^{3}$, Md Minhaj Arefin ${ }^{1}$, \\ AbeedaTasnim Reza ${ }^{4}$, Mohammad Abdul Matin ${ }^{4}$, Md. Shariful Islam ${ }^{4}$, Fahdia Afroz ${ }^{4}$, Abul Hasnat Md. Jafor ${ }^{5}$
}

\begin{abstract}
:
Background:Young women undergoing percutaneous coronary intervention (PCI) for acute coronary syndrome (ACS) experience greater short-term adverse events than young men. There is a scarcity of data on the short-term adverse outcomes between young Bangladeshi males and females with ACS undergoing PCI.Objectives: This study was conducted to compare the short-term outcomes of $\mathrm{PCl}$ between young males and females presenting with ACS. Methods: This prospective observational study was done in the Department of Cardiology, National Institute of Cardiovascular Diseases (NICVD) fromApril 2016 to March 2017. 190 young patients with ACS and undergoing $\mathrm{PCl}$ were enrolled. They were equally divided into two groups, group I (young females < 55 years) and group II (young males $<45$ years). Results: The mean age of young females and males was 43.8 \pm 6.9 years and $40.1 \pm 4.3$ years respectively. Young women had significantly higher risk factors of hypertension $(62.1 \%$ vs $33.7 \%, p<0.0010)$ and diabetes $(57.9 \%$ vs $31.6 \%$, $\mathrm{p}<0.001$ ) in comparison to young men. Overall, young women experienced significantly greater incidence of short-term adverse events in comparison to young men
\end{abstract}

$(14.7 \%$ vs. $6.3 \%, p=0.04)$ and had significantly higher rates of severe bleeding $(6.3 \%$ vs $1.1 \%, p=0.04)$, vascular access site complications $(8.4 \%$ vs $2.1 \%, p=0.04)$ and recurrent ischaemia at 30 days $(7.4 \%$ vs. $2.1 \%, p=0.04)$. Major adverse cardiac events (MACE) were higher among young females, in comparison to young males $(4.1 \%$ vs $2.1 \%, p=0.4)$. Young females experienced significantly higher rates of short-term net adverse clinical events (NACE) than young males $(10.5 \%$ vs $3.2 \%$, $p=0.04$ ). Female gender (odds ratio [OR] 11.7), diabetes (OR 2.5), hypertension (OR 1.78), decreased ejection fraction (OR 1.41) and smaller stent diameter (OR 1.15) were identified as independent predictors of adverse short-term outcomes among young ACS patients undergoing $\mathrm{PCl}$. Conclusion: Young women experienced significantly more adverse short-term outcomes after PCl. They had significantly greater NACE, largely driven by increased rates of major bleeding. Female gender was an independent predictor of adverse short-term outcomes among young ACS patients undergoing $\mathrm{PCl}$.

Key words:Acute Coronary Syndrome, Percutaneous Coronary Intervention, Young Adult, Treatment Outcome.

(Bangladesh Heart Journal 2018; 33(1): 1-9)

Introduction:

Acute coronary syndromes (ACS) are a major cause of mortality in developing countries, and are responsible for a large number of hospitalizations annually. ${ }^{1}$ Historically, women with ACS have had worse outcomes in comparison

1. Assistant Registrar, Department of Cardiology, Ibrahim Cardiac Hospital \&Research Institute, Dhaka, Bangladesh

2. Professor and Director, National Institute of Cardiovascular Diseases, Dhaka.

3. Junior Consultant, Department of Cardiology, National Institute of Cardiovascular Diseases, Dhaka.

4. Post graduate Fellow, Department of Cardiology, National Institute of Cardiovascular Diseases, Dhaka

5. Associate Professor, Department of Cardiology, National Institute of Cardiovascular Diseases, Dhaka.

Address of Correspondence: Dr Fathima Aaysha Cader, Assistant Registrar, Department of Cardiology, Ibrahim Cardiac Hospital \& Research Institute, Dhaka. Bangladesh. Mobile: +8801749419893, Email: aaysha.cader@gmail.com.

DOI: http://dx.doi.org/10.3329/bhj.v33i1.37015

Copyright $\odot 2017$ Bangladesh Cardiac Society. Published by Bangladesh Cardiac Society. This is an Open Access articles published under the Creative Commons Attribution-NonCommercial 4.0 International License (CC BY-NC). This license permits use, distribution and reproduction in any medium, provided the original work is properly cited and is not used for commercial purposes. 
to men, in data derived predominantly from the preintervention era. ${ }^{2}$ Nevertheless, even following $\mathrm{PCl}$, it has been observed that women had more adverse cardiovascular outcomes, a fact that has largely been attributed to their older age at presentation and greater co-morbidities. ${ }^{3-4}$

However, ACS is increasingly prevalent at a younger age, particularly among those of South Asian ethnicity. ${ }^{5}$ The prevalence of ACS among young women has also increased. ${ }^{6}$ There is disparity in the literature on the definition of "young" with respect to premature CAD and ACS, with the age cut-off varying from $\leq 40$ to $\leq 55$ years in various studies. ${ }^{7-9}$ Cardiovascular disease develops 7 to 10 years later in women than in men, ${ }^{10}$ leading to a difference in the definition of the "young" ACS patient for each gender,arising from the fundamental differences in the physiology of women and a protective effect of endogenous oestrogens against CAD. As such, "young" patients in relation to ACS have been defined in the literature as females $<55$ years of age, and males $<45$ years of age, a similar cut-off that has been adopted in this study. $8,9,11$

Although percutaneous revascularization is generally considered to be associated with lower risk and better recovery in young patients, multiple studies have observed that younger women were more likely than men to experience adverse cardiovascular outcomes, including in-hospital and 30-day mortality, major adverse cardiac events (MACE) and bleeding, despite similarly high angiographic and procedural success. ${ }^{12-15}$ Alternatively, a few studies have observed higher MACE among young males undergoing $\mathrm{PCl} .{ }^{16}$

Younger women were at more than twice the risk of periprocedural complications such as coronary dissection and abrupt vessel closure, ${ }^{15}$ possibly attributable to their smaller vessel size and increased tortuosity of coronaries. ${ }^{17}$ Younger women were also more likely to experience bleeding complications. ${ }^{12,14,15}$ The increased adverse outcomes among younger women with ACS may be further attributed to the clustering of cardiovascular risk factors and comorbidities, most notably diabetes, and also hypertension, cerebrovascular disease, renal impairment and congestive heart failure in comparison to men. ${ }^{12,14}$ It has been previously studied in an older Bangladeshi population, that females undergoing $\mathrm{PCl}$ have more adverse in-hospital outcomes in comparison to males, particularly coronary vascular injury and bleeding complications. ${ }^{18}$ However, there are no contemporary data on gender-related differences in shortterm outcomes of young ACS patients undergoing $\mathrm{PCl}$ in Bangladesh. This study has been designed to investigate any disparities in the short-term outcomes (i.e. composite of in-hospital and 30-day outcomes) between young male and female ACS patients following $\mathrm{PCl}$ and to identify the predictors of adverse cardiovascular outcomes in young ACS patients undergoing $\mathrm{PCl}$.

\section{Methods:}

This prospective observational study was conducted over a period of 1 year from April 2016 to March 2017 at the Department of Cardiology, National Institute ofCardiovascular Diseases (NICVD), Dhaka. The study complied with the Declaration of Helsinki. Prior ethical approval was obtained from the ethical review committee of NICVD. Informed written consent was taken from each patient. Young patients were defined as males $<45$ years and females $<55$ years in accordance with the literature A total of 190 young patients presenting with $\mathrm{ACS}$, and undergoing $\mathrm{PCl}$ during index hospitalisation at NICVD were selected by purposive sampling technique, based on predefined enrollment criteria. Patients with prior MI, mechanical complications of $\mathrm{MI}$, cardiogenic shock, valvular and congenital heart disease, cardiomyopathy, prior revascularization ( $\mathrm{PCl}$ or coronary artery bypass graft), intravenous contrast allergy, serum creatinine $>2 \mathrm{mg} / \mathrm{dl}$ and those with bleeding disorders were excluded. Study subjects were divided into two groups on the basis of gender. Group I comprised of young females and group II comprised of young males.

Patients' demographic characteristics, risk factors, ACS typeand left ventricular (LV) ejection fraction (EF) were recorded. Coronary angiography was performed by conventional method (right femoral access) by routine operators. All angiograms were evaluated by two experienced cardiologists. Angiographic variables including Gensini Score, ACC/ AHAlesion type of culprit lesion, culprit vessel and number of diseased vessels (single, double, triple) were noted. In case of angiographically significant stenosis, ad hoc $\mathrm{PCl}$ to culprit artery was done. All patients were pre-treated with standard dual antiplatelet therapy (DAPT) comprising of aspirin and clopidogrel. PCl variables including stent type, stent diameter and length, periprocedural events, angiographic, procedural and clinical success were noted. Patients were then followed up for outcome variables. Follow- up comprised of two parts: Inhospital (i.e. for the entire duration of hospital stay until time of discharge) and once again at 30-days. The following inhospital outcomes were observed and recorded: Vascular access site and peri-procedural complications, bleeding, significant arrhythmias, cardiogenic shock, acute heart failure, $\mathrm{MI}$ related to $\mathrm{PCl}$, stent thrombosis repeat revascularization, stroke and death. All patients were further followed up at the completion of 30 days following $\mathrm{PCl}$ and above-mentioned outcome variables were recorded, in addition to repeat-hospitalization and recurrent ischaemia. Overall major adverse cardiac events (MACE) and net 
adverse clinical events (NACE) were recorded. Outcome data elements were defined according to 2013 ACCF/AHA Key Data Elements and Definitions for Measuring the Clinical Management and Outcomes of Patients with Acute Coronary Syndromes and Coronary Artery Disease: A Report of the American College of Cardiology Foundation/American Heart Association Task Force on Clinical Data Standards. Presence of short-term outcome was considered as composite of in-hospital and 30-day outcome. ${ }^{19} \mathrm{~A}$ composite or overall adverse outcome was defined as consisting of the occurrence of any one of a set of multiple defined outcome variables.

Data were processed and analyzed using software using SPSS Version 16.0 (Statistical Package for the Social Sciences by SPSS Inc., Chicago, IL, USA, 2007). The test statistics used to analyze the data were descriptive statistics, Chi-squared Test $\left(\mathrm{c}^{2}\right)$, unpaired t-Test and Fisher's Exact Test.Multiple logistic regression analysis was performed to identify predictors of short-term adverse outcomes. Ap value of $<0.05$ was considered statistically significant.

\section{Results:}

A total of 190 patients were studied, including 95 young females and 95 young males. The overall mean age was $41.3 \pm 5.6$ years (range 18-54 years). The mean age of young females was $43.8 \pm 6.9$ years and young males was $40.1 \pm 4.3$ years (Table I). A total of $52.6 \%$ STEMI, $26.3 \%$ NSTEMI and
21.1\% UA patients were included with equal distribution between the two genders. Among STEMI patients, $70 \%$ were of anterior and $30 \%$ were of inferior MI.

Table II shows the distribution of risk factors between the groups. Hypertension (62.1\% vs $33.7 \%, p<0.001)$ and diabetes (57.9\% vs. $31.6 \%$, p, 0.001$)$ were significantly more prevalent among young females, while smoking was significantly greater among young males $(70.5 \%$ vs $0 \%$, $\mathrm{p}<0.001)$. Among the young females, 70 (74\%) were premenopausal, and among pre-menopausal females, $63 \%$ had history of taking oral contraceptive pill (OCP). The mean percent of left ventricular (LV) ejection fraction (EF) of study patients was $46.8 \pm 10.0$. Young females had significantly higher EF in comparison to young males $(48.4 \pm 9.3$ vs 45.1 $\pm 10.4, p=0.02$ ).

Table III shows the comparison of angiographic characteristics between the two groups. Left main coronary artery (LMCA) $(3.2 \%$ vs. $1.1 \%, p=0.61)$ andLeft anterior descending (LAD) $(51.6 \%$ vs. $45.3 \%, p=0.38)$ were more frequently involved among young females. Young males demonstrated angiographically more severe CAD, with significantly higher numbers of ACC/AHA lesion type B2 (40\% vs $25.3 \%, p=0.03)$ and $C(20 \%$ vs $9.47 \%, p=0.03)$. Young males also had greater frequency of double and triple vessel disease and higher mean Gensini scores, although not statistically significant (Table III).

Table-I

Distribution of study patients by age

\begin{tabular}{llcccc}
\hline Age in years & \multicolumn{1}{c}{ Young females $(\mathrm{n}, \%)$} & \multicolumn{2}{c}{ Young males $(\mathrm{n}, \%)$} & $\mathrm{p}$ value \\
\hline$<25$ & 3 & 3.2 & 2 & 2.1 & 0.65 \\
$25-34$ & 5 & 5.3 & 14 & 74.8 & 0.02 \\
$35-44$ & 39 & 41.1 & 79 & 83.1 & $<0.001$ \\
$45-54$ & 48 & 50.5 & $40.1 \pm 4.3(22-44)$ & $<0.001$ \\
Mean \pm SD (Range) & $43.8 \pm 6.9(18-54)$ & & $<0.001$ \\
\hline
\end{tabular}

Table-II

Comparison of risk factors for CAD between young females and males

\begin{tabular}{lccccc}
\hline Risk Factors & Young females $(\mathrm{n}, \%)$ & \multicolumn{2}{c}{ Young males $(\mathrm{n}, \%)$} & $\mathrm{p}$ value \\
\hline Smoking & 0 & 0.0 & 67 & 70.5 & $<0.001$ \\
Smokeless tobacco & 8 & 8.4 & 3 & 3.2 & 0.21 \\
Hypertension & 59 & 62.1 & 32 & 33.7 & $<0.001$ \\
Diabetes mellitus & 55 & 57.9 & 30 & 31.6 & $<0.001$ \\
Dyslipidaemia & 59 & 62.1 & 50 & 52.6 & 0.18 \\
Family H/O CAD & 41 & 43.2 & 33 & 34.7 & 0.23 \\
\hline
\end{tabular}


Table-III

Comparison of angiographic characteristics between young females and males

\begin{tabular}{|c|c|c|c|c|c|}
\hline \multirow{2}{*}{$\begin{array}{l}\text { Angiographic Characteristic } \\
\text { Culprit artery }\end{array}$} & \multicolumn{2}{|c|}{ Young females $(\mathrm{n}, \%)$} & \multicolumn{2}{|c|}{ Young males (n, \%) } & \multirow[t]{2}{*}{ p value } \\
\hline & & & & & \\
\hline Left main stem & 3 & 3.2 & 1 & 1.1 & 0.61 \\
\hline Left anterior descending & 49 & 51.6 & 43 & 45.3 & 0.38 \\
\hline Left circumflex & 17 & 17.9 & 21 & 22.1 & 0.46 \\
\hline Right coronary & 24 & 25.3 & 30 & 31.6 & 0.33 \\
\hline Ramus Intermedius & 2 & 2.1 & 0 & 0.0 & 0.47 \\
\hline \multicolumn{6}{|l|}{ Number of diseased vessels } \\
\hline Single & 66 & 69.5 & 56 & 58.9 & 0.13 \\
\hline Double & 18 & 18.9 & 21 & 22.1 & 0.58 \\
\hline Triple & 11 & 11.6 & 18 & 18.9 & 0.15 \\
\hline \multicolumn{6}{|l|}{ ACC/AHAlesion type } \\
\hline A & 38 & 40.0 & 14 & 14.7 & $<0.001$ \\
\hline B1 & 24 & 25.3 & 24 & 25.3 & 1.00 \\
\hline B2 & 24 & 25.3 & 38 & 40.0 & 0.03 \\
\hline C & 9 & 9.47 & 19 & 20.0 & 0.03 \\
\hline \multicolumn{6}{|l|}{ Gensini Score } \\
\hline Mean \pm SD & \multicolumn{2}{|c|}{$39.3 \pm 27.6$} & \multicolumn{2}{|c|}{$44.0 \pm 32.4$} & 0.27 \\
\hline
\end{tabular}

Table IV details the procedural characteristics between the two groups. Mean stent diameter was significantly smaller in young females $(2.7 \pm 0.3$ vs. $2.9 \pm 0.4 \mathrm{~mm}, \mathrm{p}=0.02)$, but no significant difference in mean stent length was seen between the two groups. Young females were significantly less likely to receive a drug eluting stent (DES) $(81.1 \%$ vs $96.8 \%, p=0.001)$. there was no significant difference in terms of angiographic and procedural success between the two groups.

Table $\mathrm{V}$ demonstrates the rates of in-hospital adverse outcomes observed between the two groups. Vascular access site complications ( $8.4 \%$ vs $2.1 \%, p=0.04)$ and bleeding ( $13.7 \%$ vs. $4.2 \%, p=0.02)$ were significantly higher among young females. All other in-hospital adverse outcomes were also observed with greater frequency among young females, albeit not statistically significant.

Table VI depicts the outcomes observed at 30 days follow up of the study subjects. Overall, young females were more likely to experience adverse outcomes in comparison to young males, particularly repeat hospitalization $(6.3 \%$ vs. $1.1 \%, p=0.04)$ and recurrent ischaemia $(7.4 \%$ vs. $2.1 \%$, $\mathrm{p}=0.04)$.
Table VII shows the comparison of composite short-term outcomes between the two groups, which were significantly higher among young females ( $14.7 \%$ vs $6.3 \%$, $p=0.04)$.At 30 days, young females showed higher rates of death $(3.2 \%$ vs. $1.1 \%, p=0.62$ ) and major adverse cardiac events (MACE) ( $4.1 \%$ vs. $2.1 \%, p=0.4)$, albeit not significant. However, it was seen that 30 -day net adverse clinical events (NACE) were significantly higher among young females $(10.5 \%$ vs. $3.2 \%, p=0.04)$, largely driven by their higher rates of GUSTO severe bleeding $(6.3 \%$ vs $1.1 \%, p=0.04)$.

Table VIII demonstrates the binary logistic regression analysis of odds ratio (OR) for characteristics of the subjects likely to develop adverse short-term outcomes. Multivariate analysis revealed that out of the 9 expected variables, female gender, hypertension, diabetes mellitus, decreased EF and smaller stent diameter were found to be the independently significant predictors of adverse short-term outcomes with odds ratios (OR) being 11.7, 1.78, 2.5, 1.41 and 1.15respectively, on multi-variate analysis. Age $>40$ years did not emerge as an independent predictor of adverse short-term outcome. 
Table-IV

Comparison of PCI Procedural characteristics between young females and males

\begin{tabular}{|c|c|c|c|c|c|c|c|}
\hline \multirow{2}{*}{$\frac{\text { PCI Variables }}{\text { Stent diameter (m }}$} & \multicolumn{2}{|c|}{ Young females(n, \%) } & \multicolumn{2}{|c|}{ Young males(n, \%) } & \multicolumn{2}{|c|}{ Total(n, \%) } & \multirow[t]{2}{*}{$p$ value } \\
\hline & & & & & & & \\
\hline 2.25 & 12 & 12.6 & 9 & 9.5 & 21 & 11.1 & 0.48 \\
\hline 2.5 & 32 & 33.7 & 16 & 16.8 & 48 & 25.3 & 0.007 \\
\hline 2.75 & 15 & 15.8 & 34 & 35.8 & 49 & 25.8 & 0.002 \\
\hline 3.0 & 30 & 31.6 & 19 & 20.0 & 49 & 25.8 & 0.06 \\
\hline 3.5 & 6 & 6.3 & 14 & 14.7 & 20 & 10.5 & 0.04 \\
\hline 4.0 & 0 & 0.0 & 3 & 3.2 & 3 & 1.6 & 0.08 \\
\hline Mean diameter & $2.7 \pm 0.3$ & $2.9 \pm 0.4$ & $2.8 \pm 0.4$ & 0.02 & & & \\
\hline \multicolumn{8}{|c|}{ Stent length (mm) } \\
\hline$<20 \mathrm{~mm}$ & 31 & 32.6 & 22 & 23.2 & 63 & 27.9 & 0.14 \\
\hline$>20$ mm & 64 & 67.4 & 73 & 76.8 & 137 & 72.1 & \\
\hline Mean $\pm S D$ & $25.0 \pm 9.6$ & $26.6 \pm 9.2$ & $25.8 \pm 9.4$ & 0.26 & & & \\
\hline \multicolumn{8}{|l|}{ Stent type } \\
\hline BMS & 18 & 18.9 & 3 & 3.2 & 21 & 11.1 & 0. .001 \\
\hline DES & 77 & 81.1 & 92 & 96.8 & 169 & 88.9 & \\
\hline \multicolumn{8}{|c|}{$\mathrm{PCl}$ procedural success } \\
\hline Angiographic & 91 & 95.8 & 94 & 98.9 & 185 & 97.4 & 0.36 \\
\hline Procedural & 90 & 94.7 & 94 & 98.9 & 184 & 96.8 & 0.21 \\
\hline Clinical & 88 & 92.7 & 93 & 97.9 & 181 & 95.2 & 0.17 \\
\hline
\end{tabular}

Table-V

Comparison of in-hospital outcomes between young females and males

\begin{tabular}{lccccc}
\hline Outcomes variables & Young females $(\mathrm{n}, \%)$ & \multicolumn{3}{l}{ Young males $(\mathrm{n}, \%) \mathrm{p}$ value } \\
\hline Peri-procedural complications & 8 & 8.4 & 3 & 3.2 & 0.21 \\
Cardiogenic shock & 6 & 6.3 & 4 & 4.2 & 0.74 \\
Heart failure & 9 & 9.5 & 6 & 6.3 & 0.42 \\
Vascular access site complications & 8 & 8.4 & 2 & 2.1 & 0.04 \\
Bleeding & 13 & 13.7 & 4 & 4.2 & 0.02 \\
Significant arrhythmia & 5 & 5.3 & 3 & 3.2 & 0.47 \\
Stroke & 0 & 0.0 & 0 & 0.0 & - \\
M & 1 & 1.1 & 0 & 0.0 & 1.00 \\
Stent thrombosis & 1 & 1.1 & 0 & 0.0 & 1.00 \\
\hline Death & 1 & 1.1 & 0 & 0.0 & 1.00 \\
\hline
\end{tabular}

Table-VI

Comparison of 30-day outcomes between young females and males

\begin{tabular}{lccccc}
\hline Outcomes variables & Young females $(\mathrm{n}, \%)$ & \multicolumn{3}{l}{ Young males $(\mathrm{n}, \%) \mathrm{p}$ value } \\
\hline Repeat hospitalization & 6 & 6.3 & 1 & 1.1 & 0.04 \\
Recurrent ischaemia & 7 & 7.4 & 2 & 2.1 & 0.04 \\
Heart failure & 5 & 5.3 & 3 & 3.2 & 0.47 \\
M & 0 & 0 & 0 & 0.0 & - \\
Stent thrombosis & 0 & 0 & 0 & 0.0 & - \\
Bleeding & 2 & 2.1 & 0 & 0.0 & 0.47 \\
Significant arrhythmia & 1 & 1.1 & 3 & 3.2 & 0.62 \\
Stroke & 0 & 0.0 & 1 & 1.1 & 1.00 \\
Repeat revascularization & 0 & 0.0 & 0 & 0.0 & - \\
Death & 2 & 2.1 & 1 & 1.1 & 1.00 \\
\hline
\end{tabular}


Table-VII

Comparison of composite/ overall adverse outcomes between young females and males

\begin{tabular}{lccccccc}
\hline Outcomes & \multicolumn{2}{c}{ Young females $(\mathrm{n}, \%)$} & \multicolumn{2}{c}{ Young males $(\mathrm{n}, \%)$} & \multicolumn{2}{c}{ Total $(\mathrm{n}, \%)$} & $\mathrm{p}$ value \\
\hline Composite/ overall & 14 & 14.7 & 6 & 6.3 & 20 & 10.5 & 0.04 \\
Overall MACE* $^{*}$ & 4 & 4.1 & 2 & 2.1 & 6 & 3.2 & 0.4 \\
Overall NACE* & 10 & 10.5 & 3 & 3.2 & 13 & 6.8 & 0.04 \\
\hline
\end{tabular}

*MACE: Major adverse cardiac event; *NACE: Net adverse clinical event.

Table-VIII

Multivariate binary logistic regression analysis for determinants of adverse short-term outcome.

\begin{tabular}{lcc}
\hline Variables of interest & $\mathrm{OR}(95 \% \mathrm{Cl})$ & P value \\
\hline Smoking & $1.30(0.599-2.210)$ & 0.11 \\
Hypertension & $1.78(1.101-3.694)$ & 0.03 \\
Dyslipidemia & $1.29(0.105-3.109)$ & 0.30 \\
Diabetes mellitus & $2.50(1.211-5.321)$ & 0.004 \\
Decreased EF $<55 \%$ & $1.41(1.002-3.420)$ & 0.02 \\
Gensini Score & $1.07(0.201-2.212)$ & 0.55 \\
Smaller stent diameter $<2.5 \mathrm{~mm}$ & $1.15(1.111-3.289)$ & 0.02 \\
Age $>40$ years & $1.03(0.412-1.782)$ & 0.70 \\
Female gender & $11.7(1.72-25.414)$ & 0.02 \\
\hline
\end{tabular}

Dependent variable: short-term adverse outcome

Independent variables: smoking, hypertension, dyslipidemia, diabetes mellitus, decreased $\mathrm{EF}<55 \%$, Gensini score, smaller stent diameter $<2.5 \mathrm{~mm}$, age $>40$ years, female gender

\section{Discussion:}

This prospective observational study presents the comparison of short-term outcomes of young ACS patients undergoing $\mathrm{PCl}$. The mean age of young females was significantly higher than young males ( $43.8 \pm 6.9$ vs $40.1 \pm 4.3$ years, $p=0.001$ ), which were slightly higher than the patient population of the PROMETHEUS study ( $48.6 \pm 5.6$ years vs. $48.1 \pm 6.0$ years), ${ }^{12}$ but is comparable to an Indian study by Patted, et al. (2017). ${ }^{16}$ The younger mean age in this study possibly reflects the earlier onset of premature atherosclerosis among South Asian populations in comparison to Western populations. ${ }^{6}$

Equal numbers of all presentations across the spectrum of ACS were taken from both groups in order to ensure matching. The majority of this young ACS population undergoing $\mathrm{PCl}$ presented with ST-elevation myocardial infarction (STEMI), accounting for $52.6 \%$ of all subjects. Anterior MI was more frequent than inferior MI. These findings concur with those of an Indian study, in which an overwhelming majority of patients underwent $\mathrm{PCl}$ due to STEMI. ${ }^{16}$ In contrast, however, Chandrasekhar, et al. (2016) observed in the PROMETHEUS study, that unstable angina (UA) comprised almost half of the study population (approximately $46 \%$ ) and STEMI comprised only approximately one quarter. ${ }^{12}$
This study observed that young females had higher frequencies of baseline risk factors, particularly hypertension and diabetes. Several other studies have made similar observations. ${ }^{12,14}$ Diabetes is a particularly strong risk factor for coronary artery disease (CAD) in women and is associated with a heightened cardiovascular mortality particularly in women $<55$ years (Lansky, et al., 2004). Some studies suggest that diabetes may also negate the protective effects of estrogen on vascular function, and increase the risks of post $\mathrm{PCl}$ complications..$^{20,21}$ Smoking, however, was observed exclusively among young males $(70.5 \%)$. While no females reported cigarette smoking, $8.4 \%$ of them gave a history of taking smokeless tobacco. These findings concur with Indian populations ${ }^{16}$ and some Western studies in which fewer females were known to be smokers. ${ }^{2,13}$ They differ from more recent studies where smoking was significantly more frequently observed among young females. ${ }^{12,14,22}$

Young females had significantly better LV systolic function than young males, and angiographically less severe CAD reflected by less frequency of multivessel disease $(30.5 \%$ vs $41 \%$ for young females vs males respectively) and lesser Gensini scores. These findings concur with previous studies. ${ }^{12,14}$ Prior studies have reported that intracoronary stents have been used less frequently among young women with ACS, although the use of DES has been more frequent 
among females or comparable among both genders. ${ }^{12,22}$ On the contrary, in our study, significantly fewer young females received a DES $(81.1 \%$ vs $96.8 \%, p=0.001)$, possibly due to financial constraints. Despite this, women have been shown to derive greater benefit from DES due to reduced intimal hyperplasia, ${ }^{23}$ and as such, a greater use of DES should be advocated.

There was no significant difference between angiographic and procedural success between the two groups, which concurs with most prior studies wherein adverse outcomes were reported, despite comparable procedural success. ${ }^{13,14}$ At 30 days, young females showed lesser clinical success owing to increased recurrent ischaemia, however, this was not statistically significant.

Young women had greater incidence of all the individual outcome variables studied, except stroke. They also had significantly higher rates of short-term composite adverse outcomes, predominantly due to significantly higher rates of recurrent ischaemia, bleeding and vascular access site complications. Significantly increased vascular access site complications was also observed in Lansky, et. al. (2004) $)^{13}$ where $9.4 \%$ vs $2.3 \%$ was reported for young women vs men respectively. Argulian, et. al. (2006) $)^{15}$ also observed similar outcomes $(7.6 \%$ vs $3.5 \%$ for young women vs men respectively).

Bleeding complications in patients with ACS are a significant predictor of adverse outcomes, morbidity and mortality. ${ }^{22}$ In particular, patients with STEMI constitute a high-risk subset of acute patients requiring urgent revascularisation on a background of aggressive pharmacological treatment including intravenous (IV) anticoagulation, IV glycoprotein Ilb/IIla inhibitors, thrombolysis and DAPT. As such, ACS patients undergoing $\mathrm{PCl}$ are more prone to vascular access complications which represent a source of major bleeding.

Multiple previous studies have also observed increased bleeding and vascular complications among young women, particularly those undergoing PCI for STEMI. ${ }^{14,15,25, \text { Such }}$ increased bleeding risk has been attributed to decreased coagulation reserve, potential overdose of anticoagulant or antiplatelet agents, and differences in platelet biology of women. ${ }^{15,26}$ Several studies have also found that younger women were more likely than men to experience periprocedural complications such as coronary dissection and abrupt vessel closure, possibly attributable to their smaller vessel size leading to difficulty in vessel manipulation and increased susceptibility to mechanical vessel injury. ${ }^{15,17,26}$ Young females showed a non-significant increase in such peri-procedural complications in our study. Furthermore, young women had significantly smaller coronary arteries as reflected by the smaller diameter stents implanted in them ( $2.7 \pm 0.3 \mathrm{~mm}$ vs. $2.9 \pm 0.4 \mathrm{~mm}$ for males). Chandrasekhar, et al. (2016) also reported smaller stent diameters $(2.94 \pm 0.5$ vs. $3.1 \pm 0.5 \mathrm{~mm}$ for females and males respectively). ${ }^{12}$ Smaller stent diameter was also a significant predictor of poor outcome on multi-variate logistic regression analysis in this study.

Estrogen, traditionally known to exert a protective effect on vascular endothelial function in pre-menopausal women, has also been suggested as a possible reason for the increased risk of vascular injury complications in younger women, given that most women $<55$ years old are premenopausal. ${ }^{15}$ Estrogen may increase the level of various coagulation factors and inflammatory markers and affects vascular endothelial function and its reaction to circulating vasoactive factors. Alternatively, the protective influence of estrogen may be over-ridden by the presence of risk factors, particularly diabetes, resulting in worse outcomes for young women with ACS compared with young men. ${ }^{15}$ (Argulian, et al., 2006). Further studies on the presence of specific estrogen receptors and their relationship with adverse outcomes among women are warranted.

At 30 days follow up, young females reported significantly more repeat hospitalisation $(6.3 \%$ vs. $1.1 \%, p=0.04)$ most likely due to significantly higher recurrent ischaemia $(7.4 \%$ vs. $2.1 \%$ ). Some authors have postulated that the morbidity of angiographically non-obstructive (i.e. non-atherosclerotic) CAD is greater in women, leading to recurrent angina and adverse outcomes. ${ }^{23,27}$

Young females had greater incidence of combined in hospital and 30-day major adverse cardiac events (MACE) in our study $(4.1 \%$ vs $2.1 \%$ for young women and men respectively), which was not statistically significant $(p=0.4)$. Lansky, et al. (2004) also observed no significant difference in major in-hospital complications constituting MACE (3.1\% vs $0.6 \%$ respectively). ${ }^{13}$ Neither did Argulian, et al. (2006) who found rates of $4.1 \%$ vs $4.0 \%$ for males and females respectively. ${ }^{15}$ Abramson, et al. (2003) reported an adjusted relative risk of 1.78 for increased in-hospital mortality post $\mathrm{PCl}$ for females over males. ${ }^{17}$ Srinivas, et al. (2007) reported a statistically significant increase of post-PCl in-hospital mortality following acute $\mathrm{Ml}$ in young females $(0.42 \%$ vs. $0.05 \% ; p=0.0007$ ), with female sex found to be an independent predictor of MACE. ${ }^{14}$ Chandrasekhar, et al. (2016) reported a 90-day MACE of $9.6 \%$ for young females in comparison to $7.6 \%$ for young males. ${ }^{12}$ In contrast to the above studies, a recent Indian study by Patted, et al. (2017) reported an insignificant increase in MACE among young males undergoing $\mathrm{PCl}$ in a predominantly ACS sample population. ${ }^{16}$ 
Consequent to a significantly greater bleeding risk and insignificant increase in MACE, both groups were evaluated for net adverse clinical events (NACE), a term first defined in the HORIZONS-AMI study, and found that women had significantly higher incidence of short-term NACE $(10.5 \%$ vs $3.2 \%, p=0.04$ ), largely owing to their increased rates of major bleeding.

On multivariate logistic regression analysis, this study showed that hypertension, diabetes, reduced ejection fraction, smaller stent diameter and female gender were independent predictors of adverse short-term outcomes in ACS patients after PCl. Both Srinivas, et al. (2007) and Lansky, et al. (2004) in their studies found that female gender was an independent predictor of mortality, vascular complications and MACE. ${ }^{13,14}$ The presence of greater comorbidities among females is a contributing factor to their adverse outcomes, as observed by Chandrasekhar, et al. (2016). ${ }^{12}$ There are many differences in mechanisms of ACS and plaque characteristics between young males and females that may be attributed to such differences in post$\mathrm{PCl}$ outcome (Chandrasekhar and Mehran, 2016). ${ }^{23}$ These biological differences in atherosclerosis between men and women have not been entirely clarified, and further studies using intravascular ultrasound (IVUS) and optical coherence tomography (OCT) may be helpful in defining predictors of gender-based adverse outcome among young patients.

In addition to female gender, risk factors such as hypertension and diabetes mellitus also emerged as independent predictors of adverse outcome among young ACS patients undergoing $\mathrm{PCl}$. Young females with ACS are known to present with a greater clustering of these risk factors in comparison to young males, and the presence of such co-morbidities, rather than female gender per se may have been responsible for their increased incidence of adverse cardiovascular outcome. Alternatively, the fact that young women have more hypertension and diabetes could also mean the presentation of ACS itself is more often than not, complicated by these co-morbidities in young women, and could be considered as a holistic clinical entity leading to adverse outcomes, rather than separate disease processes. Having said that, in order to overcome this limitation, further studies with matching of the number of hypertensive and diabetic patients among the two genders are warranted, to independently test purely for the effect of gender on adverse outcome after PCl.

\section{Limitations:}

This study was not without limitations. The study population was relatively smallsingle center study.Sampling method was non-random, so there was risk of selection bias. It was not a single operator study, therefore there may be variation in outcome according to operator expertise.

\section{Conclusion:}

This study demonstrated that young women presenting with ACS had significantly more short term adverse outcomes after $\mathrm{PCl}$ than young men. Despite angiographically less severe $C A D$, young women had significantly increased rates of recurrent ischaemia and repeat hospitalisation. They also had higher rates of MACE including death, although not statistically significant. Young women had significantly higher rates of bleeding and vascular complications, in comparison to young men, resulting in significantly greater incidence of NACE, a composite of MACE and major bleeding. Female gender, diabetes, hypertension, decreased ejection fraction and smaller stent diameter were identified as independent predictors of adverse short-term outcomes.

\section{References:}

1. Murray CJ, Lopez AD. Mortality by cause for eight regions of the world: Global Burden of Disease Study. Lancet. 1997;349(9061):1269-76.

2. Vaccarino V, Parsons L, Every NR, Barron HV, Krumholz HM. Sex-based differences in early mortality after myocardial infarction. National Registry of Myocardial Infarction 2 Participants. N Engl J Med. 1999;341(4):217-25.

3. Yu J, Mehran R, Grinfeld L, Xu K, Nikolsky E, Brodie $B R$, et al. Sex-based differences in bleeding and long term adverse events after percutaneous coronary intervention for acute myocardial infarction: three-year results from the HORIZONS-AMI trial. Catheter Cardiovasc Interv. 2015;85(3):359-68.

4. Hess CN, McCoy LA, Duggirala HJ, Tavris DR, O'Callaghan K, Douglas PS, et al. Sex-based differences in outcomes after percutaneous coronary intervention for acute myocardial infarction: a report from TRANSLATE-ACS. J Am Heart Assoc. 2014;3(1):e000523.

5. Islam AKMM, Majumder AAS. Coronary artery disease in Bangladesh: A review. Indian Heart J. 2013; 65(4): 424-435.

6. Towfighi A, Zheng L, Ovbiagele B. Sex-specific trends in midlife coronary heart disease risk and prevalence. Arch Intern Med. 2009;169(19):1762-1766. 386.

7. Shah N, Kelly AM, Cox N, Wong C, Soon K. Myocardial Infarction in the "Young": Risk Factors, Presentation, Management and Prognosis. Heart Lung Circ. 2016; 25(10), pp.955-960. 
8. Mohammad AM, Jehangeer HI, Shaikhow SK. Prevalence and risk factors of premature coronary artery disease in patients undergoing coronary angiography in Kurdistan, Iraq. BMC Cardiovascular Disord. 2015; 15:155.

9. Zuhdi AS, Mariapun J, Hairi NNM, Ahmad WAW, Abidin IZ, Undok AWet al. Young coronary artery disease in patients undergoing percutaneous coronary intervention. Ann Saudi Med. 2013; 33(6):572-578

10. Maas AHEM, Appelman YEA, 2010. Gender differences in coronary heart disease. Neth Heart J. 2010; 18(12): 598-602.

11. Al-Murayeh M, Al-Masswary A, Dardir M, Moselhy M, Youssef A. Clinical presentation and short-term outcome of acute coronary syndrome in native young Saudi population. J Saudi Heart Assoc. 2012; 24(3):169-175.

12. Chandrasekhar J, Baber U, Sartori S, Faggioni M, Aquino M, Kini A, et al. Sex-related differences in outcomes among men and women under 55 years of age with acute coronary syndrome undergoing percutaneous coronary intervention: Results from the PROMETHEUS study. Catheter Cardiovasc Interv. 2017;89(4):629-637

13. Lansky AJ, Mehran R, Dangas G, Cristea E, Shirai K, Costa R,et al. Comparison of differences in outcome after percutaneous coronary intervention in men versus women $<40$ years of age. Am J Cardiol. 2004; 93:916-9

14. Srinivas VS, Garg S, Negassa A, Bang JY, Monrad ES. Persistent sex difference in hospital outcome following percutaneous coronary intervention: results from the New York State reporting system. J Invasive Cardiol. 2007;19:265-268.

15. Argulian E, Patel AD, Abramson JL, Kulkarni A, Champney K, Palmer S, et al. Gender differences in short-term cardiovascular outcomes after percutaneous coronary interventions. Am J Cardiol. 2006;98:48-53.

16. Patted SV, Porwal SC, Halkati PC, Ambar S, Prasad $\mathrm{MR}$, Metgudmath VB,et al. Comparison of Clinical profile and outcome between young $(\leq 45 y \mathrm{rs})$ male and female patients with coronary artery disease undergoing percutaneous coronary intervention, a single center study. Journal of Medical Science and Clinical Research. 2017; 05(02):17919-17925.

17. Abramson JL, Veledar E, Weintraub WS, Vaccarino V. Association between gender and In-Hospital mortality after percutaneous coronary intervention according to age. Am J Cardiol. 2003;91:968-71.

18. Roy US. In-hospital outcome after percutaneous coronary interventions in women and men [MD Cardiology thesis]. Dhaka: University of Dhaka; 2008.

19. Cannon CP, Battler A, Brindis RG, Cox JL, Ellis SG, Every NR,et al. American College of Cardiology key data elements and definitions for measuring the clinical management and outcomes of patients with acute coronary syndromes. A report of the American College of Cardiology Task Force on Clinical Data Standards (Acute Coronary Syndromes Writing Committee). J Am Coll Cardiol. 2001;38(7):2114-30.

20. Flaherty JD, Davidson CJ.Diabetes and coronary revascularization. JAMA. 2005;293(12):1501-1508.

21. Kawano H, Motoyama T, Ohgushi M, Kugiyama K, Ogawa $\mathrm{H}$, Yasue $\mathrm{H}$. Menstrual cyclic variation of myocardial ischemia in premenopausal women with variant angina. Ann Intern Med. 2001;135(11):.977-981

22. Epps KC, Holper EM, Selzer F, Vlachos HA, Gualano SK, Abbott JD, et al. Sex Differences in Outcomes Following Percutaneous Coronary Intervention According to Age. Circ Cardiovasc Qual Outcomes. 2016;9(2 Suppl 1):S16-S25.

23. Chandrasekhar J, Mehran R. Sex-Based Differences in Acute Coronary Syndromes. JACC CardiovasC Imaging 2016;9(4):451-464.

24. Manoukian SV. Predictors and impact of bleeding complications in percutaneous coronary intervention, acute coronary syndromes, and ST-segment elevation myocardial infarction. Am J Cardiol 104: 9C-15C.

25. Lichtman JH, Wang Y, Jones SB, Leifheit-Limson EC, Shaw LJX, Vaccarino V, et al. Age and sex differences in inhospital complication rates and mortality after percutaneous coronary intervention procedures: evidence from the $\mathrm{NCDR}\left({ }^{\circledR}\right)$. Am Heart J. 2014;167(3):376-83.

26. Numasawa Y, Kohsaka S, Miyata H, Noma S, Suzuki M, Ishikawa S, et al. Gender Differences in In-Hospital Clinical Outcomes after Percutaneous Coronary Interventions: An Insight from a Japanese Multicenter Registry. PLoS ONE. 2015; 10(1):e0116496.

27. Bairey Merz CN, Shaw LJ, Reis SE, Bittner V, Kelsey $\mathrm{SF}$, Olson M,et al. Insights from the NHLBI-Sponsored Women's Ischemia Syndrome Evaluation (WISE) Study: Part II: gender differences in presentation, diagnosis, and outcome with regard to gender-based pathophysiology of atherosclerosis and macrovascular and microvascular coronary disease. J Am Coll Cardiol. 2006;47: S21-9. 